www.jmscr.igmpublication.org

Impact Factor (SJIF): 6.379

Index Copernicus Value: 71.58

ISSN (e)-2347-176x ISSN (p) 2455-0450

crossref DOI: https://dx.doi.org/10.18535/jmscr/v6i6.117

Journal Of Medical Science And Clinical Research

IGM Publication

An Official Publication of IGM Publication

\title{
Histopathological Evaluation of Hyperplastic Endometrial Lesion based on New WHO classification
}

\author{
Authors \\ Dr Shikha Ghanghoria ${ }^{1}$, Dr C.S. Chhatrasal ${ }^{2 *}$, Dr Varsha Argal $^{3}$ \\ ${ }^{1}$ Professor in Pathology Department, M.G.M. Medical College Indore \\ ${ }^{2}$ Associate Professor in Department of Pathology, M.G.M. Medical College Indore \\ ${ }^{3}$ PG resident in Pathology Department, M.G.M. Medical College Indore \\ *Corresponding Author \\ Dr C.S. Chhatrasal \\ Associate Professor in Department of Pathology, M.G.M. Medical College Indore, MP India \\ Email:drcs-gmc@yahoo.com, Phone no-9827766946
}

\begin{abstract}
Introduction: Endometrial hyperplasia is defined as an increase in the proliferation of endometrial glands relative to stroma, resulting in increased gland to stroma ratio. It is most commonly occurred due to unopposed oestrogen action. In recent past the most widely used system divided endometrial hyperplasia into four categories: simple hyperplasia without atypia; complex hyperplasia without atypia; simple atypical hyperplasia; complex atypical hyperplasia. Recently WHO collapse the four categories into two as non atypical hyperplasia and atypical hyperplasia (also referred as endometrial intraepithelial neoplasia).

Aims: 1) To study comparison between the old and new WHO classification of endometrial hyperplasia.

2) To find out the age wise incidence of these lesions.

3) To estimate the incidence of benign and malignant lesions.

Methods and Material: Retrospective study of cases of endometrial lesions diagnosed as endometrial hyperplasia in M.Y. hospital Indore during 10 year duration. The cases with endometrial hyperplasia were reclassified according to new WHO classification.

Results: Among 600 cases of endometrial hyperplasia 94\% cases are of non atypical hyperplasia while $6 \%$ cases are of atypical hyperplasia. Majority of the cases are between 41 to 60 year of age. $35 \%$ atypical hyperplasia cases they turned out to be malignant while only $0.5 \%$ cases without hyperplasia are converted to malignancy.

Conclusions: Recently WHO classified endometrial hyperplasia as non atypical and atypical hyperplasia (endometrial intraepithelial neoplasia). It is better than old one as it represents an important simplification for clinical practice, particularly with regard to choice of treatment. Non atypical hyperplasia are treated conservatively while for atypical hyperplasia hysterectomies are done.

Keywords: Endometrial Hyperplasia, Endometrial Carcinoma, New WHO Classification.
\end{abstract}




\section{Introduction}

Endometrial hyperplasia leads to increase in gland-to-stroma ratio due to excessive and continuous stimulation of the endometrium by oestrogen. ${ }^{(1)(3)} \mathrm{EH}$ clinically presents with abnormal uterine bleeding ${ }^{(2)}$. There incidences are 133-208 per 100,000 woman-years whereas the incidences of subtypes are 121 per 100,000 woman-years for non-atypical $\mathrm{EH}$ and 16.8 per 100,000 woman-years for atypical ${ }^{(4)}$. EH Risk factors are chronic anovulation, polycystic ovary syndrome, obesity, tamoxifen therapy, and oestrogen-only hormone therapy ${ }^{(3)}$

In 1994, the WHO classified endometrial hyperplasia's into 4 categories:

1. Simple hyperplasia without atypia,

\section{Hyperplasia without atypia}

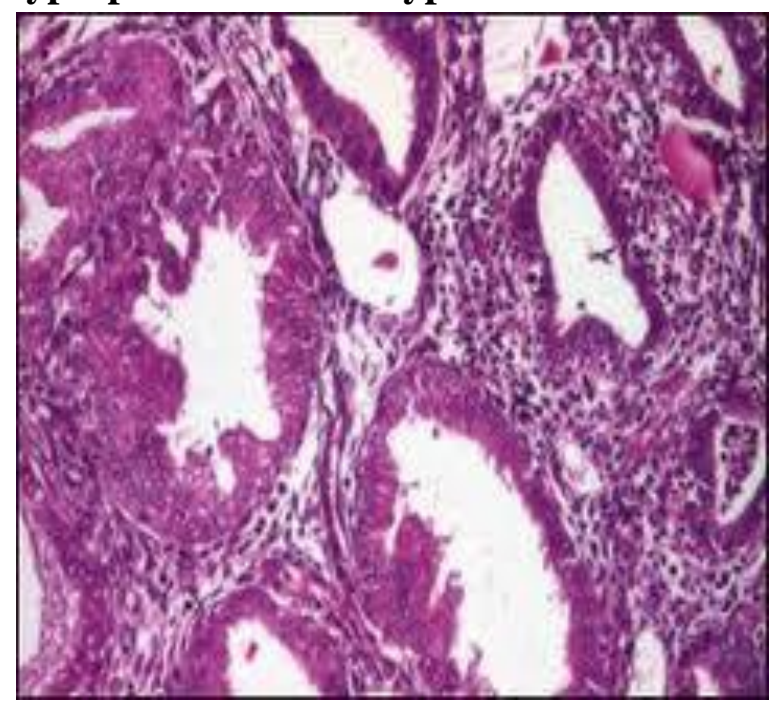

\section{Atypical hyperplasia}

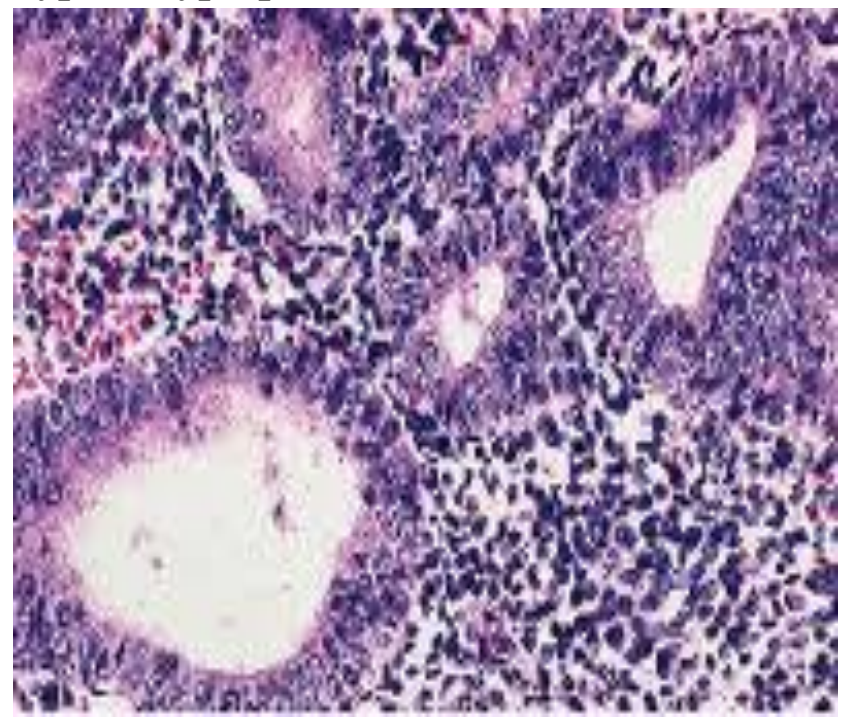

2. Complex hyperplasia without atypia,

3. Simple atypical hyperplasia,

4. Complex atypical hyperplasia ${ }^{(5),(6)}$

\section{Subjects and Methods}

A retrospective study was carried out for cases of endometrial lesions diagnosed as endometrial hyperplasia in M.Y. hospital Indore during 10 year duration. 600 endometrial hyperplasia cases were first classified according to older WHO classification. These cases of endometrial hyperplasia were reclassified as per new WHO classification. Follow up was done to estimate how much cases undergone hysterectomies or the number of cases converted to malignancy.
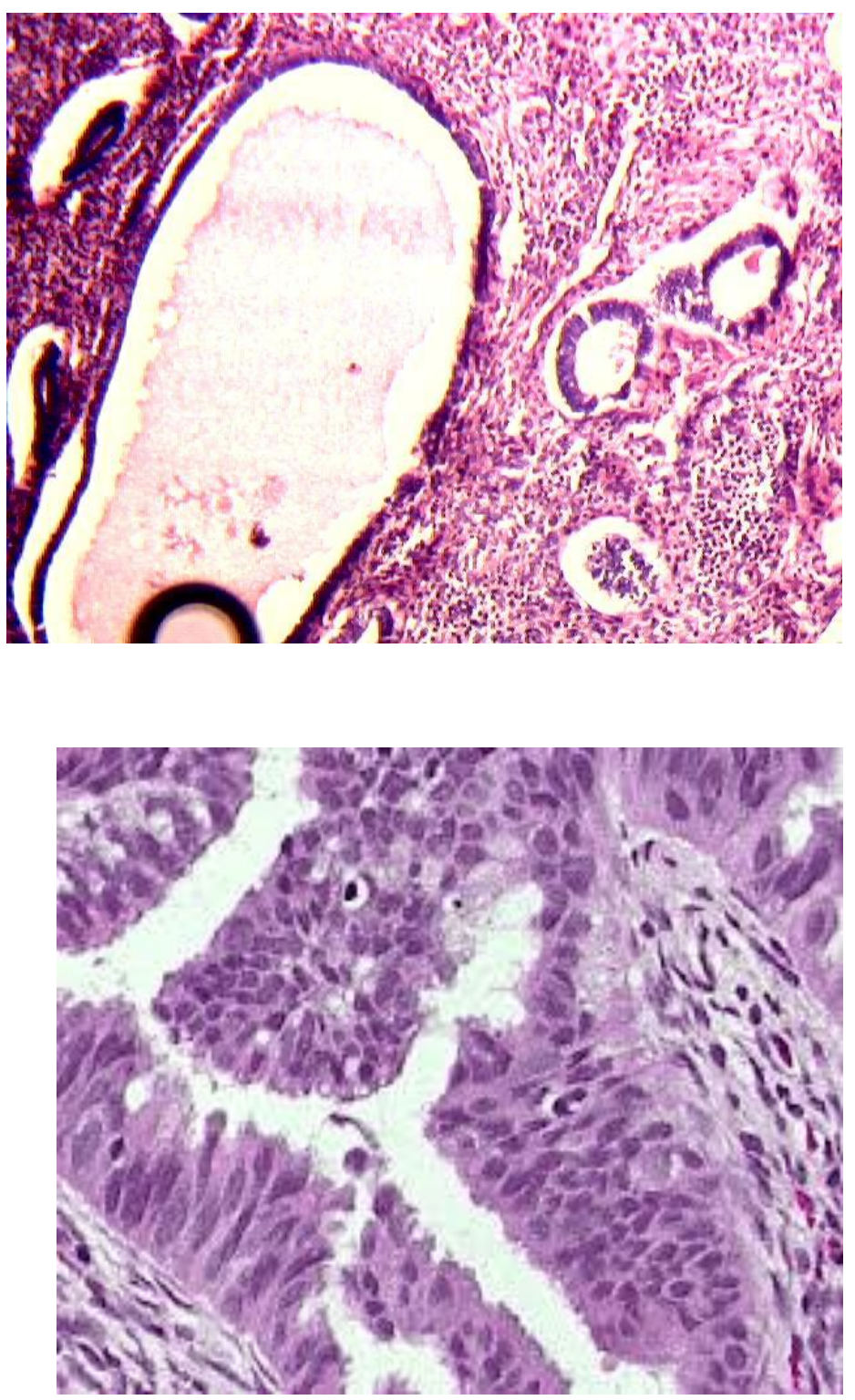
Results

Incidences of hyperplastic lesions as per old WHO classification

\begin{tabular}{|l|c|}
\hline Simple Endometrial Hyperplasia without atypia & 488 \\
\hline Complex Endometrial Hyperplasia without atypia & 78 \\
\hline Simple atypical hyperplasia & 16 \\
\hline Complex atypical hyperplasia & 18 \\
\hline Total & 600 \\
\hline
\end{tabular}

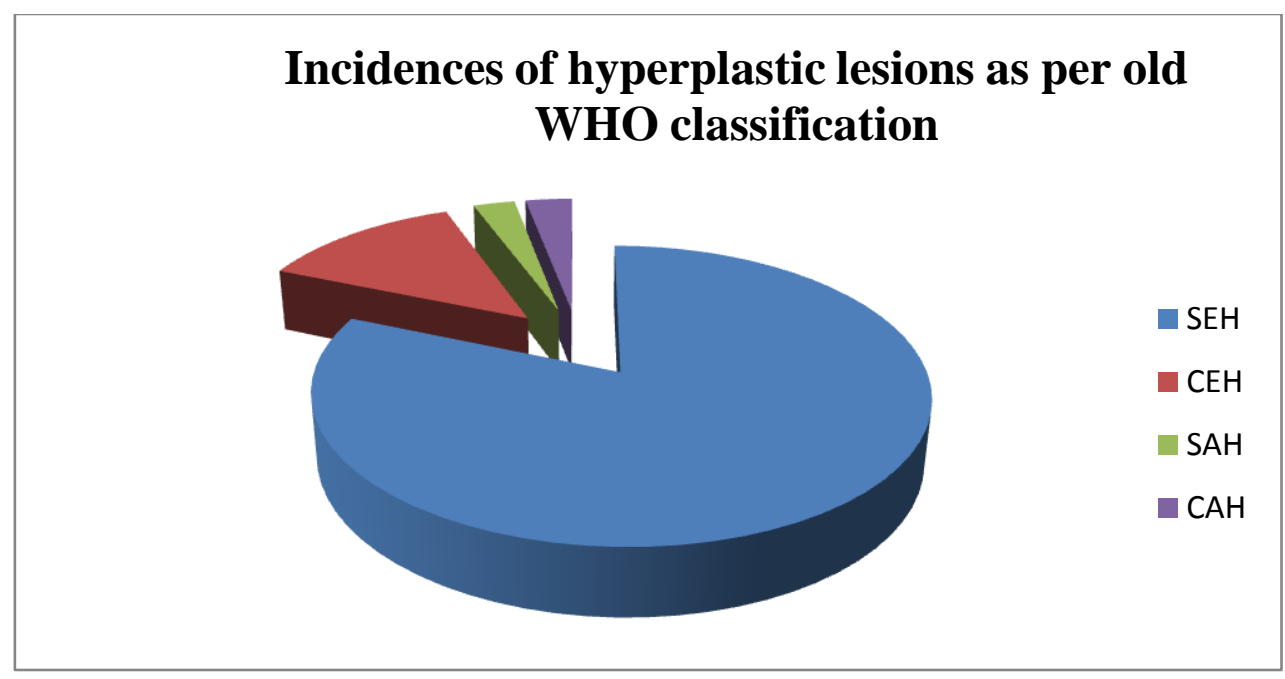

Incidences of hyperplastic lesions as per new WHO classification -

\begin{tabular}{|l|c|}
\hline Hyperplastic lesions & No of cases \\
\hline Hyperplasia without atypia & 566 \\
\hline Atypical endometrial hyperplasia & 34 \\
\hline total & 600 \\
\hline
\end{tabular}

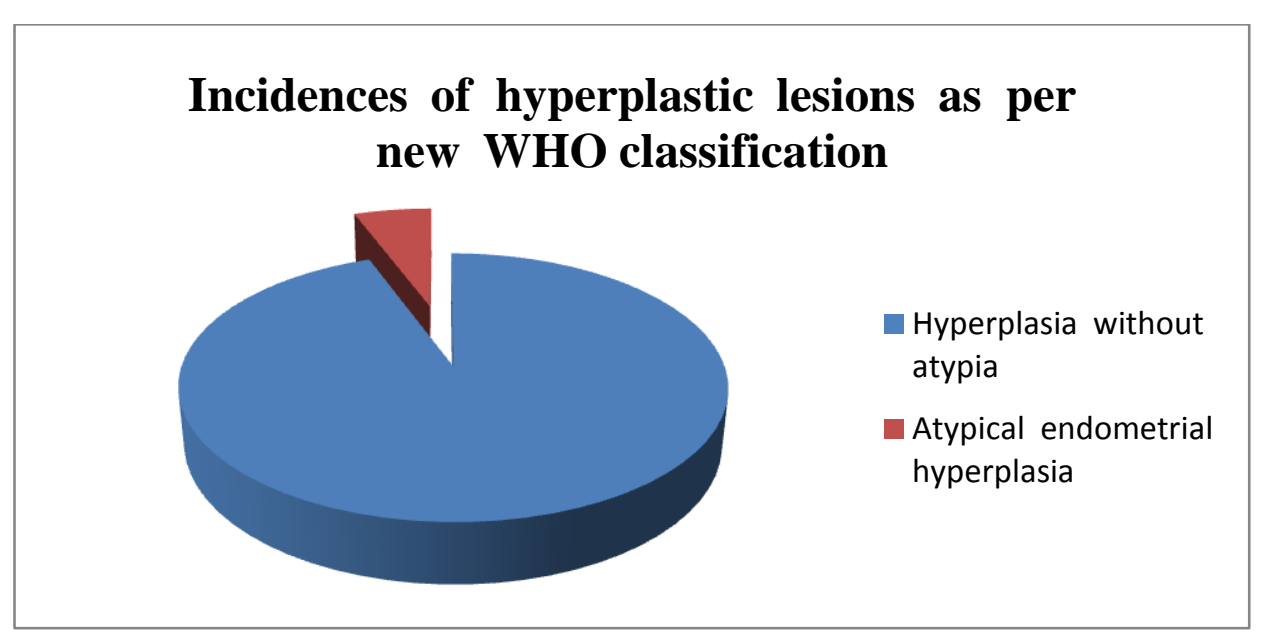

Age wise distribution

\begin{tabular}{|l|c|}
\hline Age & No. of cases \\
\hline $21-40$ & 240 \\
\hline $41-60$ & 330 \\
\hline $61-80$ & 30 \\
\hline
\end{tabular}

According to old WHO classification

Progression to endometrial carcinoma found in

\begin{tabular}{|l|c|}
\hline Simple endometrial hyperplasia without atypia & $0 \%$ \\
\hline Complex endometrial hyperplasia without atypia & $1.2 \%$ \\
\hline Simple atypical hyperplasia & $31 \%$ \\
\hline Complex atypical hyperplasia & $38 \%$ \\
\hline
\end{tabular}




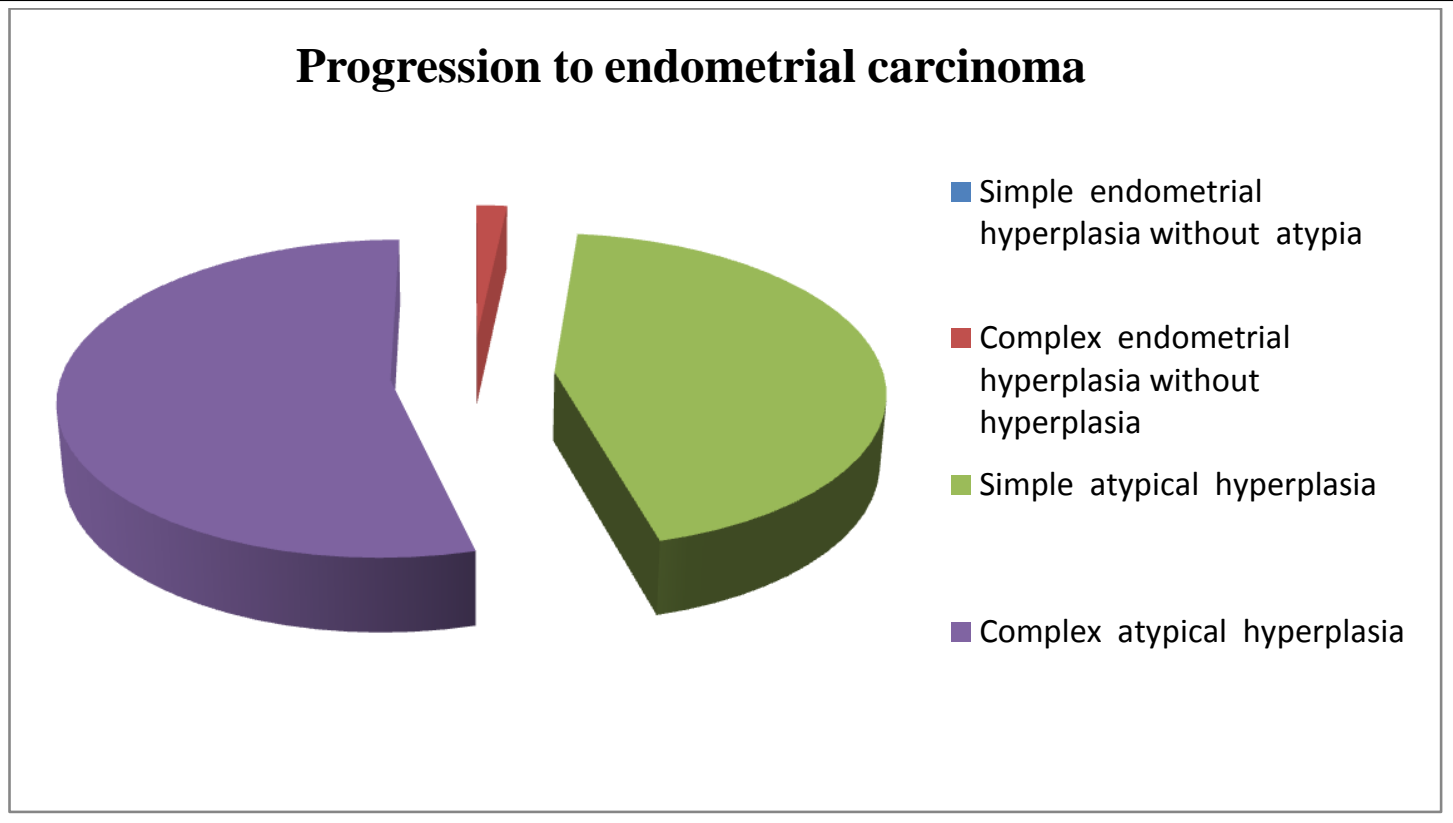

\section{According to new WHO classification}

Progression to endometrial carcinoma found in

\begin{tabular}{|l|c|}
\hline HYPERPLASIA & Progression to carcinoma \\
\hline Hyperplasia without atypia & $0.5 \%$ \\
\hline Atypical hyperplasia & $35 \%$ \\
\hline
\end{tabular}

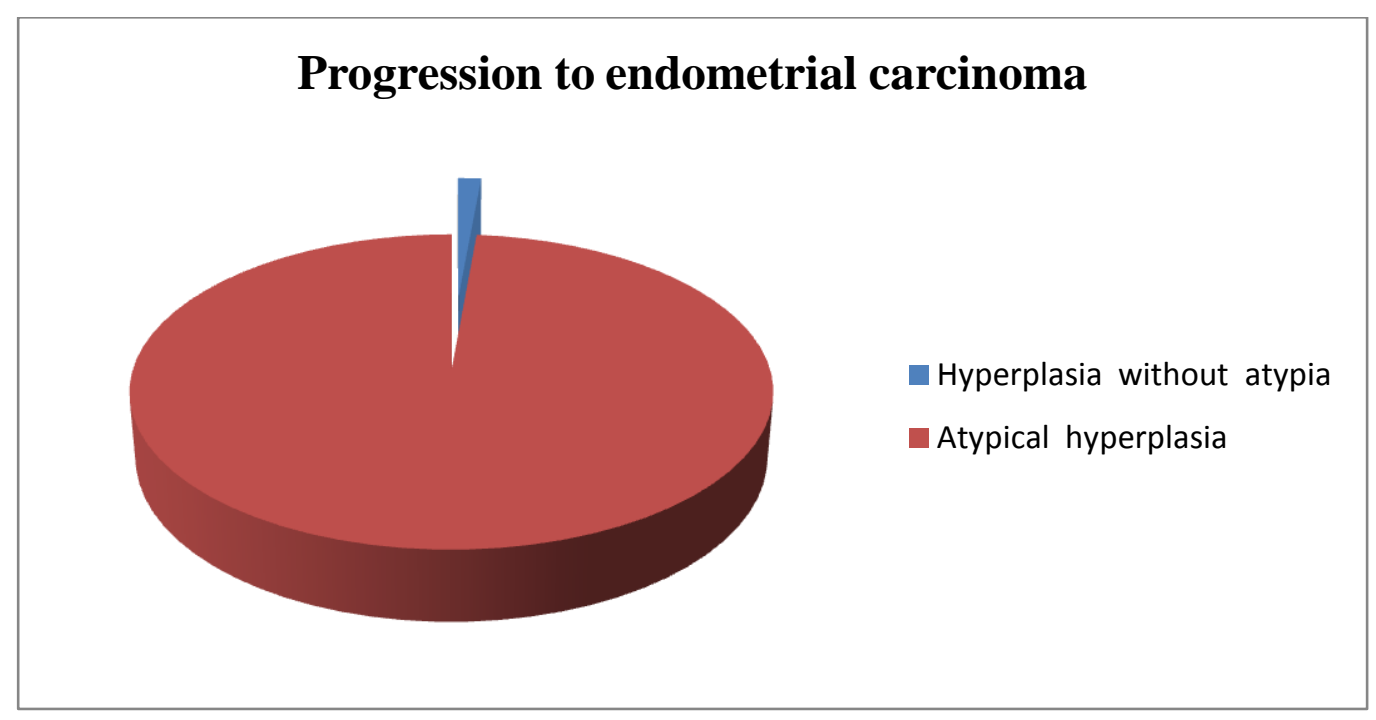

\section{Discussion}

Baak et al., 2005a; Mutter et al., 2008 suggest that $40 \%$ of women diagnosed with EIN will have an EC diagnosed within 12 months of index biopsy.

München et all shows In up to $60 \%$ of cases of atypical endometrial hyperplasias patients have coexisting invasive cancer or are at extremely high risk of developing invasive cancer
Usan D. REED et al in Incidence of Endometrial Hyperplasia suggest that Endometrial hyperplasia simple and complex hyperplasia occurs in the early $50 \mathrm{~s}$ and atypical in early $60 \mathrm{~s}$.

Baak and Mutter, 2005 found that the four-tier WHO 94 system does not straightforwardly correspond to the separate therapeutic options available (i.e. surgical, medical or observational) which may contribute to a tendency for surgical overtreatment due to the fear of 
malignant progression for lesions with no underlying sinister mechanism (Baak et al., 2001).

Trimble C L et al suggest that hyperplasias without atypia should generally be treated conservatively (normalization of the cycle through weight loss, metformin; oral contraceptives; cyclical gestagens; gestagen IUD). Preventive hysterectomy should only be considered in exceptional cases (e.g., extreme obesity without any prospect of weight loss) ${ }^{(5),(7)}$ The surgery should be done as a total hysterectomy, i.e., it must include removal of the cervix ${ }^{(7)}$.

In present study we have found that around $35 \%$ cases turned to malignancy, where maximum cases lies in between 41 to 60 years.

\section{References}

1. Ellenson LH, Ronnett BM, Kurman RJ Precursor lesions of endometrial carcinoma. In: Kurman RJ, Ellenson LH, Ronnett BM (eds). Blaustein's Pathology of the Female Genital Tract. Boston, MA: Springer, 2011;359-392.

2. Lidor A, Ismajovich B, Confino E, David MP. Histopathological findings in 226 women with post-menopausal uterine bleeding. Acta Obstet Gynecol Scand 1986; 65:41-43.

3. Epplein et al., 2008; Carlson et al., 2012; Armstrong et al., 2012) Diagnosis and management of endometrial hyperplasia. Armstrong AJ, Hurd WW, Elguero S, Barker NM, Zanotti KM J Minim Invasive Gynecol. 2012 Sep-Oct; 19(5):562-71.

4. Reed et al., 2009; Lacey et al., 2012). incidence of endometrial hyperplasia. Reed $S D$, Newton KM, Clinton WL, Epplein M, Garcia R, Allison K, Voigt LF, Weiss NS Am J Obstet Gynecol. 2009 Jun; 200(6):678.e1-6.
5. Kommission

Uterus

der

Arbeitsgemeinschaft Gynäkologische Onkologie e.V.. München: W. Zuckschwerdt $\quad$ Verlag; 2008. Interdisziplinäre S2k-Leitlinie für die Diagnostik und Therapie des Endometriumkarzinoms; pp. 73-126.

6. Owings R A, Quick C M. Endometrial intraepithelial neoplasia. Arch Pathol Lab Med. 2014;138:484-491.

7. Trimble C L, Method M, Leitao M. et al. Management of endometrial precancers. Obstet Gynecol. 2012;120:1160-1175 